\title{
Peer cultural socialisation: a resource for minority students' cultural identity, life satisfaction, and school values
}

\author{
Jana Vietze, Linda P. Juang \& Maja K. Schachner
}

To cite this article: Jana Vietze, Linda P. Juang \& Maja K. Schachner (2019): Peer cultural socialisation: a resource for minority students' cultural identity, life satisfaction, and school values, Intercultural Education, DOI: 10.1080/14675986.2019.1586213

To link to this article: https://doi.org/10.1080/14675986.2019.1586213

\section{○}

(C) 2019 The Author(s). Published by Informa

UK Limited, trading as Taylor \& Francis Group.

曲 Published online: 30 Apr 2019.

Submit your article to this journal $\widetilde{ }$

III Article views: 31

View Crossmark data $\nearrow$ 


\title{
Peer cultural socialisation: a resource for minority students' cultural identity, life satisfaction, and school values
}

\author{
Jana Vietze (iD) ${ }^{a}$, Linda P. Juang (D) and Maja K. Schachner ${ }^{a}{ }^{a, b}$ \\ aDepartment of Inclusive Education, University of Potsdam, Potsdam, Germany; ${ }^{\mathrm{b} C o l l e g e}$ for \\ Interdisciplinary Educational Research (CIDER), Berlin Social Science Center, Berlin, Germany
}

\begin{abstract}
This study investigated how peers can contribute to cultural minority students' cultural identity, life satisfaction, and school values (school importance, utility, and intrinsic values) by talking about cultural values, beliefs, and behaviours associated with heritage and mainstream culture (peer cultural socialisation). We further distinguished between heritage and mainstream identity as two separate dimensions of cultural identity. Analyses were based on self-reports of 662 students of the first, second, and third migrant generation in Germany (Mean age $=14.75$ years, $51 \%$ female). Path analyses revealed that talking about heritage culture with friends was positively related to heritage identity. Talking about mainstream culture with friends was negatively associated with heritage identity, but positively with mainstream identity as well as school values. Both dimensions of cultural identity related to higher life satisfaction and more positive school values. As expected, heritage and mainstream identity mediated the link between peer cultural socialisation and adjustment outcomes. Findings highlight the potential of peers as socialisation agents to help promote cultural belonging as well as positive adjustment of cultural minority youth in the school context.
\end{abstract}

\author{
ARTICLE HISTORY \\ Received 16 October 2018 \\ Accepted 16 October 2018
}

\section{KEYWORDS}

Peer cultural socialisation; cultural identity; cultural minority youth; life satisfaction; school motivation

\section{Introduction}

School is the primary context for formal education, but also for forming a cultural sense of self among peers from different cultural backgrounds (Motti-Stefanidi et al. 2012). Cultural socialisation, the process of learning about cultural values, beliefs, and behaviours, helps youth develop a positive cultural identity (Hughes et al. 2006). Cultural identity comprises feelings of belonging, values, and attitudes toward one's own cultural group or groups (Phinney et al. 2001), and it is related to better psychological adjustment, including well-being, and school adjustment, including school-related attitudes, of cultural minority youth (Rivas-Drake et al. 
2014). Cultural socialisation may take place as part of formal education, for example in intercultural education or dialogue as part of the curriculum, but also informally through peer networks in schools. Importantly, children spend increasing amounts of time with their peers throughout adolescence (Brown and Larson 2009), and peers become one of the most important socialisation agents for maintaining and learning about culture through cultural socialisation (Wang, Benner, and Kim 2015; Wang and Benner 2016). In addition, the peer context holds high potential to positively influence youth' life satisfaction, achievement, and academic motivation (Lynch, Lerner, and Leventhal 2013; Rogers, Niwa, and Way 2017; Ryan 2000).

In this study, we analyse how peers can contribute to cultural identity, life satisfaction, and positive school values of cultural minority students in Germany. Our research adds to the existing literature in three different ways. First, we investigate how peers with diverse cultural backgrounds may function as socialisation agents for two cultural identity dimensions, namely the identification with one's heritage and with the mainstream culture. Second, we analyse how cultural identity dimensions individually contribute to cultural minority students' life satisfaction, as well as subjective school values. School values comprise school-related importance, utility, and intrinsic values, which are key components of school achievement and success (Eccles 2005). Finally, we analyse how peer cultural socialisation indirectly relates to cultural minority students' life satisfaction and subjective school values, mediated by heritage and mainstream identity.

\section{Cultural identity and cultural socialisation}

Cultural identity has served as an umbrella term to include two dimensions, namely the identification with one's heritage, ethnic culture (i.e. heritage identity) ${ }^{1}$ and with mainstream, national culture (i.e. mainstream identity; Schotte, Stanat, and Edele 2017; Horenczyk 2010). A considerable body of research has investigated the combination of both heritage and mainstream identity within a bicultural identity framework (e.g. Benet-Martínez and Haritatos 2005; Huynh, Nguyen, and Benet-Martínez 2011), and associations with various indicators of positive youth adjustment (see Nguyen and Benet-Martínez 2013, for a review). However, the combination of the heritage and mainstream dimensions may not be strictly comparable across studies (van de Vijver 2017), and both heritage and mainstream identity individually contribute to cultural minority youth adjustment indicators (e.g. Schachner, van de Vijver, and Noack 2018). Thus, in this study, we consider both cultural identity dimensions separately.

Most studies on cultural socialisation have been conducted with ethnic and racial minorities in the USA (see Hughes et al. 2006, for a review). In developmental psychology, the process of ethnic-racial socialisation is traditionally defined as parent-to-child transmission of the racial or ethnic heritage and history, of cultural customs and traditions, to promote a sense of cultural 
group belonging and to prepare for racially and ethnically diverse societies (Hughes et al. 2006). In a similar notion, cross-cultural psychologists have defined cultural socialisation as the deliberate transmission of heritage cultural content, in contrast to enculturation, which describes the individual's acquisition of cultural competences (Berry et al. 2011). Recently, the term cultural socialisation has been defined more broadly to include the preservation and transmission of heritage as well as mainstream culture content (Juang et al. 2016; Wang, Benner, and Kim 2015). In this study, we investigate two separate dimensions of peer cultural socialisation, namely peer heritage socialisation and peer mainstream socialisation (Wang and Benner 2016), and their unique associations with heritage and mainstream identity.

Learning about different cultures may be of special importance to youth of the second or third migrant generation, who are likely to identify with and combine more than one culture (Huynh, Nguyen, and Benet-Martínez 2011; Vietze et al. 2018). Parent heritage socialisation, the parental transmission of the heritage culture and group membership, relates to various aspects of cultural minority youth' identity, such as identity centrality, meaning the importance of the cultural group as part of the self-image (Juang et al. 2016), but also a higher cultural identity exploration and commitment (Juang and Syed 2010; Umaña-Taylor, Bhanot, and Shin 2006), two key processes that describe seeking heritage culture-related information and choosing important life values for achieving a stable, secure identity (Marcia 1980). To our knowledge, there are few comparable studies investigating parent mainstream socialisation and the associations with aspects of cultural identity (see Juang et al. 2016, for an exception).

As European societies, neighbourhoods, and school environments become increasingly culturally diverse, majority youth may become a numeric minority in classrooms and inter-cultural contact may increase (see Thijs and Verkuyten 2014, for an overview). Cultural minority students are likely to befriend not only peers from their heritage culture group but also peers from other cultural groups, such as the majority or other minorities (Schachner et al. 2016b). In previous research, cultural minority youth identified more strongly with their heritage culture when interacting with same-heritage peers as opposed to differentheritage peers (Kiang and Fuligni 2009). However, cultural socialisation practices by peers and their associations with cultural identity remain understudied (Wang and Benner 2016). Therefore, we individually assessed peer cultural socialisation by a same-heritage friend and a different-heritage friend to account for differences in how their socialisation would relate to cultural identity.

\section{The role of cultural identity for life satisfaction and school values}

To fully function and participate in society as adults, cultural minority youth need not only to do well but also feel well (Ward 2001). Life satisfaction has been repeatedly linked to youth' school success and acculturative experiences 
in the German context (Schachner, van de Vijver, and Noack 2014, 2018; Pfafferott and Brown 2006). In this study, we explore life satisfaction as an indicator of positive psychological adjustment of cultural minority students.

Educational research has often targeted achievement differences between cultural minority and majority students. In this paper, we expand this view by investigating cultural minority students' subjective school values as an indicator of school adjustment. These comprise Eccles' (1983) main dimensions of schoolrelated importance, utility, and intrinsic values to promote individual school success. Importance describes the students' perception of whether school can fulfil their personal need for confirmation of the self (Eccles 2005). For example, students see school as important when they also assign high personal value to being good at school. Utility describes more instrumental aspects of school, comparable to extrinsic motivation (Deci and Ryan 1987). Students reporting high utility believe that school can serve their individual plans and goals. Intrinsic values fall within the scope of intrinsic motivation, and describe students' relatively stable positive emotional and cognitive evaluation of school, including students' personal interests in a specific subject or topic discussed at school. All three dimensions are the basis for future goal setting and successful learning of cultural minority and majority youth (Andriessen, Phalet, and Lens 2006), but have rarely been explored simultaneously with cultural minority students in Germany. Our study aims to fill this gap.

A positive sense of cultural belonging relates to a variety of positive individual developments, such as protection against feelings of confusion, fear, or threat caused by discrimination experiences (see Vedder and van Geel 2017, for an overview). A strong heritage identity is related to a broad array of adjustment indicators, including academic engagement, achievement, and prosocial behaviour (Rivas-Drake et al. 2014). A large body of acculturation research supports that a high identification with both cultures is related to favourable psychological and school adjustment of cultural minority youth (Nguyen and Benet-Martínez 2013; Makarova and Birman 2016). In contrast, in recent studies from Germany, only cultural minority youths' mainstream identity was associated with school achievement (Schotte, Stanat, and Edele 2017; Hannover et al. 2013; Schachner, van de Vijver, and Noack 2018), whereas both heritage and mainstream identity were associated with psychological adjustment, including higher life satisfaction and reduced problem behaviour (Schotte, Stanat, and Edele 2017; Schachner, van de Vijver, and Noack 2018). Some authors have argued that the German school context might hold particularly high assimilative pressures, where students are expected to adapt to the mainstream culture while neglecting their heritage culture (Hannover et al. 2013; Bender-Szymanski 2012). Therefore, in an assimilative school context, emphasising mainstream identity might be more important for school success than heritage identity (Makarova and Birman 2016; Schotte, Stanat, and Edele 2017). An alternative explanation is that a more developed heritage identity may be indirectly associated with achievement through 
psychological adjustment (Schachner, van de Vijver, and Noack 2018). We add to this discourse and investigate cultural minority youths' associations between cultural identity, life satisfaction, and school values within the German school context.

Developmental psychologists have shown that parent heritage socialisation is directly associated with a variety of positive psychological and school adjustment outcomes (see Hughes et al. 2006, for a review), including achievement, engagement, and school belonging (Gartner, Kiang, and Supple 2014; Wang and Benner 2016; Dimitrova, Johnson, and van de Vijver 2017). More recently, parental mainstream socialisation has also been linked to positive school adjustment of cultural minority youth (Wang and Benner 2016). Importantly, heritage and mainstream identity may mediate the relationship between parent heritage socialisation and psychological and school adjustment (Gartner, Kiang, and Supple 2014; Dimitrova, Johnson, and van de Vijver 2017; Schachner, van de Vijver, and Noack 2014). In this study, we add to previous research by investigating this mediational effect among peers, and between perceived peer heritage and mainstream socialisation with life satisfaction and school values of cultural minority students.

\section{The current study}

In Germany today, every third child has at least one parent or grandparent not born in Germany, though most of these children have German citizenship (Göttsche 2017). In 1996, the Ministers of Education of the German federal states formally incorporated intercultural learning into the school curricula (Faas 2008). A recent shift towards diversity pedagogy has added to ongoing efforts to formally address cultural diversity as the norm in German classrooms (Hüpping and Büker 2014). In this study, we investigate how the more informal transmission of cultural values, beliefs, and behaviours through peers can relate to cultural minority youth' cultural identity and adjustment. More precisely, we investigate associations between peer cultural socialisation (i.e. peer heritage and mainstream socialisation) and cultural identity (i.e. heritage and mainstream identity), and between cultural identity and adjustment outcomes (i.e. life satisfaction and subjective school values), and indirect associations between peer cultural socialization and adjustment outcomes, mediated by cultural identity.

Hypothesis 1: Drawing on parent and peer cultural socialisation research (e.g. Wang and Benner 2016), we expected that high levels of peer heritage socialisation would be related to a more developed heritage identity $(\mathrm{H} 1 \mathrm{a})$. Accordingly, perceiving high levels of peer mainstream socialisation would be related to a more developed mainstream identity $(\mathrm{H} 1 \mathrm{~b})$. As an additional exploratory research question, we investigated if these relations differed 
when the socialising peer belonged to the same-heritage culture or a different-heritage culture group (RQ1c).

Hypothesis 2: Based on international findings on cultural identity and adjustment (e.g. Nguyen and Benet-Martínez 2013), we expected that high levels of identification with the heritage culture and mainstream culture would both be positively related to life satisfaction and school values $(\mathrm{H} 2 \mathrm{a})$. However, in line with research from Germany, we also expected mainstream identity to be more strongly related to school values than heritage identity (H2b) (Schotte, Stanat, and Edele 2017; Hannover et al. 2013; Schachner, van de Vijver, and Noack 2018).

Hypothesis 3: Drawing on cultural socialisation research relating to parents (Gartner, Kiang, and Supple 2014; Dimitrova, Johnson, and van de Vijver 2017), we anticipated that peer cultural socialisation would be indirectly associated with adjustment outcomes, and that this link would be mediated by cultural identity. More precisely, we expected that peer heritage socialisation would relate to adjustment outcomes through a stronger heritage identity and peer mainstream socialisation through a stronger mainstream identity $(\mathrm{H} 3)$.

As important covariates, we added participants' gender and socioeconomic status (SES). Gender was included because cultural minority girls have shown advantages in educational achievement compared to boys (e.g. Feliciano 2012). Also, gender variations in psychological and school adjustment have been related to differences in experiencing stress, acculturative hassles, and cultural socialisation between girls and boys (Güngör and Bornstein 2013; Schachner, van de Vijver, and Noack 2018; Suárez-Orozco and Qin 2006). We included SES because it is confounded with minority and migration status and also accounts for differences in educational aspirations and values (Kao and Tienda 1998).

\section{Method}

\section{Participants}

We used a subsample from a cross-sectional survey collected with a total of $13359^{\text {th }}$ graders in 17 culturally diverse secondary schools in Berlin, Germany. To test our hypotheses, we first selected only students with a migrant background, meaning participants with at least one parent, grandparent, or themselves born outside of Germany or with a mother tongue other than German $(N=1055)$. Next, a total of 393 participants were excluded due to more than $20 \%$ missing data on the study variables. To explore this large amount of missing data, we investigated which cultural group or groups participants self-identified with. Participants with a migrant background had self-labelled as exclusively mainstream (i.e. German; $N=347$ ), 
as exclusively heritage (e.g. Turkish; $N=249$ ), as dual-mainstream (e.g. German-Turkish; $N=434$ ), as dual-heritage (e.g. Norwegian-Turkish; $N=24$ ), or as other/no cultural label (e.g. human; $N=1$ ). Most mainstream identifiers skipped questions about heritage culture (66\% missing values) and peer heritage socialisation (68\% missing values), and therefore did not allow for meaningful multigroup comparisons between self-labelled groups. Thus, analyses were conducted with a combined sample of mainstream, heritage, dual, and non-cultural identifiers with less than $20 \%$ missing data on the study variables.

Our final sample comprised 662 students of migrant background $\left(M_{\text {age }}\right.$ $=14.75$ years, $S D_{\text {age }}=.76,51 \%$ female). One in five participants belonged to the first migrant generation ( $21 \%$ born outside of Germany), and more than half were of the second and third migrant generation $(62 \%$ with at least one parent, and $9 \%$ with at least one grandparent born outside of Germany). Apart from the mainstream culture, participants self-identified as part of large minority groups, such as of Turkish- (20.9\%), Polish- (5.9\%), or Russian-heritage (3.8\%).

Students in this study either attended Gymnasium (22.2\%), which is the academic track preparing students for university, or an Integrated Secondary School (ISS, 77.8\%), which combines the former vocational and comprehensive school types, and offers all variations of school leaving certificates. In Berlin, students receive recommendations for secondary school tracks based on their academic performance in primary school. However, this recommendation can be biased, with students of migrant background being less likely to be recommended to academic-track schools than their majority peers (Söhn and Özcan 2006). The composition in this study reflects this underrepresentation.

\section{Procedure and measures}

Participants were surveyed during class time. The questionnaire was presented in German, the schools' main language of instruction. Participation was voluntary and based on permission from the Berlin Senate, school authorities, and parents. A pilot study with 43 cultural minority and majority students provided reliability and validation information for all items and scales prior to the study. Apart from the self-labelling questions, participants responded on a 5-point Likert scale from (1) no, that's not right to (5) yes, that's right. Descriptive statistics and reliabilities of subscales are depicted in Table 1.

\section{Peer heritage and mainstream socialisation}

This scale was based on the Cultural Socialization Scale (Wang, Benner, and Kim 2015). The measure was translated, shortened and reformulated to refer to a single close friend. Participants were asked to indicate one close friend from their own heritage culture and one close friend from a different heritage culture. For each 


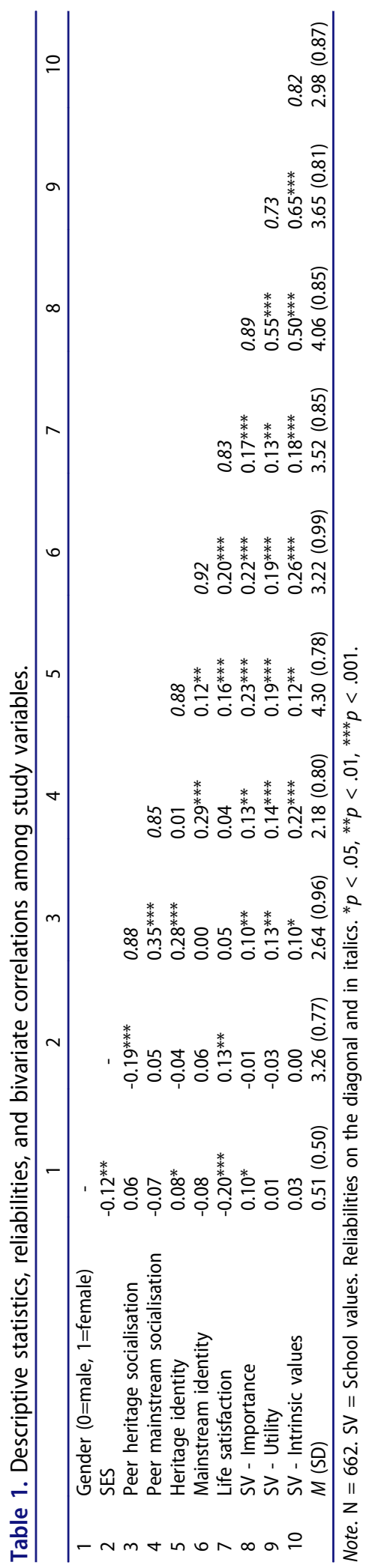


friend, five items measured peer heritage socialisation (e.g. 'My friend talks to me about values and beliefs of my heritage culture' or 'My friend encourages me to be proud of my heritage culture'), and five items measured peer mainstream socialisation (mirrored to peer heritage socialisation items; e.g. 'My friend talks to me about values and beliefs in Germany'). Yet, high bivariate correlations ( $r=.68$ between heritage socialisation, and $r=.80$ between mainstream socialisation by sameculture and different-culture friends) indicated that participants did not sufficiently differentiate between both friends' socialisation practices to justify an individual subscale for each friend. Therefore, to counter multicollinearity concerns in the analyses, we combined both friends' items into one mean score for peer heritage socialisation and one mean score for peer mainstream socialisation, with higher scores indicating higher perceived amounts of peer socialisation.

\section{Heritage and mainstream identity}

We used the German Measure of Youth's Ethnic and National Identity (Leszczensky and Santiago 2015) to assess cultural belonging through evaluative and emotional aspects of participants' cultural identities. Mean scores were calculated so that higher scores indicated higher identification with the heritage or mainstream culture. Seven items formed the heritage identity subscale and seven items formed the mainstream identity subscale. In each subscale, two items addressed the evaluative component of each identity (e.g. 'I am glad to belong to my family's heritage culture/Germany'), one item addressed cultural pride ('I am proud to belong to my family's heritage culture/Germany'), and four items regarded the emotional component of each identity (e.g. 'It bothers me if somebody speaks ill about my family's heritage culture/Germany').

\section{Life satisfaction}

We assessed general life satisfaction with the Satisfaction With Life Scale (SWLS; Diener et al. 1985), comprising five items (e.g. 'I am satisfied with my life'), and translated and validated for cultural minority youth in Germany (Ponizovsky et al. 2013). Mean scores were calculated so that higher scores indicated higher life satisfaction.

\section{Subjective school values}

We used the 9-item Scale Assessing Subjective Task Values in the School Context, which is well-established in the German context (Skala zur Erfassung subjektiver schulbezogener Werte, SESSW; Steinmayr and Spinath 2010). The instrument measured three components of subjective task values related to school. Three items each targeted importance (e.g. 'It is important for me to be good at school'), utility (e.g. 'School is useful for my future'), and intrinsic values (e.g. 'I find the things we learn in school interesting'). In line with Steinmayr and Spinath (2010), 
confirmatory factor analysis indicated the best solution for one latent factor predicted by the three components (with factor loadings between .80 and .88).

\section{Covariates}

One item assessed gender ('What is your gender?') with the response options (0) male and (1) female. The 4-item Family Affluence Scale (Boyce et al. 2006) assessed various forms of capital as an indicator for socioeconomic status (SES): materialfinancial capital ('Does your family own a car?'; with response options 0, 1, 2 or more), human-cultural capital ('How many times did you travel away on holiday with your family during the past 12 months?', and 'How many computer and/or tablets does your family own?'; 0, 1, 2, 3 or more), and social capital ('Do you have a bedroom for yourself?'; (0) no, (1) yes). Because of the different measurement levels of SES items, we performed a categorical principal components analysis (CATPCA) and included factor loadings in the final model (Batista-Foguet et al. 2004).

\section{Analytic strategy}

First, we considered bivariate correlations between study variables to better understand relations between participants' cultural identity, peer cultural socialisation, life satisfaction, school values, and covariates. To test hypotheses, we then conducted a regression path analysis in Mplus 7.3 Muthén and Muthén (1998 [2011]), using full information maximum likelihood estimation for missing data, which is considered best practice. We assessed model fit using the comparative fit index (CFI), with values above .95 indicating good fit, and the root mean squared error of approximation (RMSEA), with values up to .08 representing an adequate fit of the model (Hu and Bentler 1999). Indirect effects were computed using bootstrapping procedures with 1000 samples and a 95\% confidence interval.

\section{Results}

\section{Preliminary analyses}

Descriptive statistics and bivariate correlations between study variables are presented in Table 1. Bivariate correlations indicated that participants who identified strongly with the heritage culture also identified more strongly with the mainstream culture. This reflects that the majority of participants identified with both the heritage and mainstream culture (dual-mainstream identifiers), but may also be an indication of cultural salience, meaning that participants generally found cultural identities a more or less important part of their self-identification (Kiang, Supple, and Stein 2018). Correlations further indicated that girls were more likely to report a more developed heritage identity and lower life satisfaction than boys. Participants with a higher SES also scored higher on life satisfaction and lower on peer heritage socialisation. Furthermore, participants with a high life satisfaction 
also reported higher levels of school importance, utility, and intrinsic values. Participants who perceived high levels of peer heritage socialisation also perceived more peer mainstream socialisation.

\section{Testing the conceptual model with path analysis}

A main goal of this study was to explore direct associations between peer cultural socialisation and youth' cultural identity, and between cultural identity and both adjustment outcomes, namely life satisfaction and school values. Our conceptual model also assumed full mediation between peer cultural socialisation (heritage and mainstream) and adjustment outcomes by participants' respective cultural identity. ${ }^{2}$ Yet, modification indices suggested adding two additional paths from peer mainstream socialisation, one to heritage identity and a direct path to school values. To further increase model fit, we allowed correlated errors between peer cultural socialisation indicators, between heritage and mainstream identity, and between both adjustment outcomes. The resulting model showed a good fit, $X^{2} /$ $\mathrm{df}=2.65, p<.001 ; \mathrm{CFI}=.96 ; \mathrm{RMSEA}=.05(95 \% \mathrm{Cl} .04$ to .07$)$. Table 2 provides an overview of all standardised direct and indirect effects from peer cultural

Table 2. Standardised direct and indirect effects and standard errors of peer cultural socialisation on adjustment outcomes via heritage and mainstream identity.

\begin{tabular}{|c|c|c|c|c|c|c|}
\hline \multirow[b]{3}{*}{ Predictors } & \multicolumn{6}{|c|}{ Adjustment outcomes } \\
\hline & \multicolumn{3}{|c|}{ Life satisfaction } & \multicolumn{3}{|c|}{ School values } \\
\hline & $\begin{array}{l}\text { Direct } \\
\text { (SE) }\end{array}$ & $\begin{array}{l}\text { Indirect via HI } \\
\text { (SE) }\end{array}$ & $\begin{array}{l}\text { Indirect via MI } \\
\text { (SE) }\end{array}$ & $\begin{array}{l}\text { Direct } \\
\text { (SE) }\end{array}$ & $\begin{array}{l}\text { Indirect via HI } \\
\text { (SE) }\end{array}$ & $\begin{array}{l}\text { Indirect via MI } \\
\text { (SE) }\end{array}$ \\
\hline $\begin{array}{l}\text { Peer heritage } \\
\text { socialisation }\end{array}$ & - & $\begin{array}{r}0.06^{* * *} \\
(.01)\end{array}$ & - & - & $\begin{array}{r}0.06^{* * *} \\
(.02)\end{array}$ & - \\
\hline $\begin{array}{l}\text { Peer mainstream } \\
\text { socialisation }\end{array}$ & - & $\begin{array}{r}-0.02^{*} \\
(.01)\end{array}$ & $\begin{array}{r}0.05^{* * *} \\
(.01)\end{array}$ & $\begin{array}{r}0.15^{* *} \\
(.04)\end{array}$ & $\begin{array}{r}-0.02^{*} \\
(.01)\end{array}$ & $\begin{array}{r}0.07^{* * * *} \\
(.02)\end{array}$ \\
\hline
\end{tabular}

Note. $\mathrm{HI}=$ heritage identity, $\mathrm{Ml}=$ mainstream identity. ${ }^{*} p<.05,{ }^{* *} p<.01,{ }^{* * *} p<.001$.

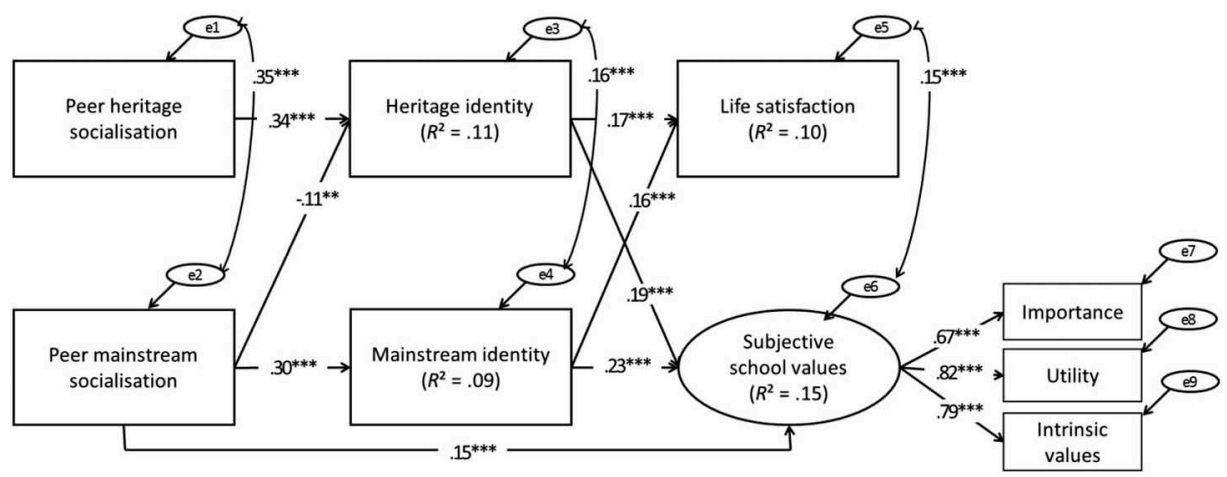

Figure 1. Path model of peer cultural socialisation, cultural identity, and life satisfaction and school values among cultural minority youth in Germany. Standardised regression coefficients. Life satisfaction and school values controlled for gender and socioeconomic status. $N=662$. ${ }^{* *} p<.01 .{ }^{* * *} p<.001$. 
socialisation to adjustment outcomes. Standardized regression coefficients and proportions of variance explained are illustrated in Figure 1.

In line with hypothesis 1 , peer cultural socialisation was positively linked to participants' cultural identity. Peer heritage socialisation was indeed positively associated with participants' heritage identity ( $\mathrm{H} 1 \mathrm{a})$, and peer mainstream socialisation was positively associated with mainstream identity $(\mathrm{H} 1 \mathrm{~b})$. However, participants who perceived high levels of peer mainstream socialisation also reported lower levels of heritage identity. Due to high bivariate correlations between subscales, we could not explore different associations if the socialising peer belonged to the same-heritage or a different-heritage culture group (RQ1c).

Partly supporting hypothesis 2 , participants' heritage and mainstream identity were both associated with more life satisfaction and higher school values, including school importance, utility, and intrinsic values ( $\mathrm{H} 2 \mathrm{a})$. It was possible to constrain the paths to be equal between both cultural identity dimensions (heritage and mainstream identity) and life satisfaction and also between cultural identity dimensions and school values, without a decrease in model fit. Therefore, against predictions, mainstream identity was not more strongly associated with school values than heritage identity $(\mathrm{H} 2 \mathrm{~b})$.

Supporting hypothesis 3 , heritage and mainstream identity served as mediators between peer cultural socialisation and adjustment outcomes (H3). Standardised indirect effects revealed that heritage identity fully mediated the link between heritage socialisation and both adjustment outcomes, and between mainstream socialisation and life satisfaction (see Table 2). Mainstream identity also mediated the link between mainstream socialisation and adjustment outcomes. However, all indirect effects were rather small. Importantly, beyond indirect effects, results revealed a direct positive relation between peer mainstream socialisation and school values.

In summary, confirming our predictions, frequently talking with peers about heritage culture was directly associated with students' more developed heritage identity and indirectly with higher life satisfaction and school values (through higher heritage identity). Talking with peers about mainstream culture was directly linked to students' higher levels of mainstream identity, but also to lower levels of heritage identity, and indirectly to adjustment outcomes (through higher levels of mainstream identity and lower levels of heritage identity). Finally, talking with peers about mainstream culture was directly related to more positive school values, beyond mainstream identity.

\section{Discussion}

The aim of this study was to test how talking about cultural values, beliefs, and behaviours with peers (peer cultural socialisation) relates to cultural minority youths' cultural identity in Germany. Furthermore, we investigated how students' cultural identity relates to adjustment outcomes, namely life satisfaction 
and subjective school values, including importance, utility, and intrinsic values related to school. This study contributes to educational research on cultural minority youths' cultural identity and psychological and school adjustment in several ways.

First, we add to previous research that apart from parents, peer cultural socialisation practices may closely and positively relate to youth' cultural identity by cooperatively maintaining and learning about values, beliefs, and behaviours of the heritage and mainstream culture (Wang, Benner, and Kim 2015). Participants who frequently talked about heritage culture with friends identified more strongly with their heritage culture. When frequently talking about the mainstream culture with friends, participants identified more strongly with mainstream culture, reported more positive school values, but also identified less strongly with their heritage culture. In a country with a strong public integration debate, such as Germany, talking about mainstream culture may entail talking about the pressure to adapt to the mainstream culture while disregarding one's heritage culture. Public assimilation expectations may therefore not only be transmitted through media and policies, but also in schools (Makarova and Birman 2016) and among peers in daily, informal interactions. To counter strong assimilation pressures, school can also function as a safe environment for sharing and exploring cultural experiences beyond the mainstream culture with friends. This may further support cultural minority youth to achieve a positive cultural identity (Vedder and van Geel 2017) and navigate academic and acculturative challenges. Therefore, we need to increase the visibility of peers as important cultural socialisation agents in research on formal and informal education.

Second, our study underlines cultural minority students' benefits from sharing cultural experiences with peers from the same-heritage as well as a differentheritage culture. Participants in this study did not sufficiently differentiate between both friends' cultural socialisation practices. This suggests that the relation between peer contact and cultural identity is indeed bidirectional (Vedder and van Geel 2017; Kiang and Fuligni 2009). Talking about culture with close friends may promote the identification with a culture. Yet, strongly identifying with a culture may also increase the motivation to talk about cultural experiences with close friends from various cultural backgrounds. Also, cultural identity may already influence the initial selection of friends who share a cultural affiliation or affiliations (Jugert, Leszczensky, and Pink 2018) and friends might already be similar in their cultural identification (Syed and Juan 2012).

Third, we provide further evidence that heritage and mainstream identity may individually mediate the relationship between cultural socialisation and positive youth adjustment (e.g. Dimitrova, Johnson, and van de Vijver 2017). In line with previous research, the identification with the heritage and mainstream culture individually helped explain psychological and school adjustment of cultural minority youth in Germany (e.g. Schachner, van de Vijver, and 
Noack 2018). In contrast to previous research from Germany (e.g. Schotte, Stanat, and Edele 2017), mainstream identity was not more strongly related to school adjustment than heritage identity. In contrast to achievement or language skills, cultural minority youth may be less disadvantaged regarding subjective school values as an indicator of school adjustment, and have shown to exceed their mainstream peers in terms of academic goals (Feliciano and Lanuza 2015). As a practical implication, intercultural education in schools may help address cultural labels to enhance a mutual understanding for cultural differences (Stevick 2017), to prepare for participation in a culturally diverse world (Vedder and van Geel 2017), and to stimulate cultural socialisation with friends. Cultural identity interventions in school have shown that students who explored their identity have higher self-esteem and do better in school one year later (Umaña-Taylor et al. 2017). Importantly, addressing cultural labels may illustrate the existing cultural heterogeneity and bring experiences of cultural inclusion or exclusion to the foreground of explaining educational disparities (Hüpping and Büker 2014).

Despite the contribution of our study findings, several limitations should be noted. A major limitation of the current study is its cross-sectional nature, which does not allow for causal assumptions. Future longitudinal research, daily diaries, and network analyses may further clarify directions of effects and questions of friendship reciprocity (e.g. Stark, Leszczensky, and Pink 2017). Despite controlling for important covariates, our results only explained a small amount of variance of the variables of interest. Therefore, we acknowledge again that cultural identity is highly dependent on close relational contexts, on societal, political and ideological conditions, but also on personal experiences (e.g. ethnic and racial discrimination) related to being a minority group member (Motti-Stefanidi et al. 2012). Another important limitation is the high amount of missing data among participants who exclusively self-labelled as part of the mainstream culture. This might have been due to the questionnaire design, where all students were encouraged to fill out questions regarding the mainstream culture and socialisation, but had the option to skip questions regarding the heritage culture and socialisation if they did not claim this cultural label. Future research may thus either be more specific about mandatory questions, or provide all participants with the same opportunity to only answer questions regarding their self-identified cultural group or groups.

\section{Conclusion}

In conclusion, our study suggests that peer cultural socialisation may hold potential for cultural minority students' cultural identity, but also for their wellbeing and school success. A primary novel contribution is the investigation of peer cultural socialisation and how it positively relates to different cultural 
identity dimensions. Importantly, cultural identity is related to a broad array of youth psychological and school adjustment indicators (Rivas-Drake et al. 2014). Peers may further contribute in an informal manner to intercultural education and skills in order to promote respect, understanding, and solidarity among individuals and nations (UNESCO 2006). Finally, our results support recent claims to move away from deficit oriented perspectives in educational research and to recognizing cultural minority youth's own potential, strengths, and resources (Titzmann and Juang 2017). Schools may be encouraged to regard the student body as a resource and to involve students in creating culturally inclusive spaces and practices in line with the heterogeneous needs of the student population (Civitillo et al. 2017). Embracing cultural pluralism and regarding diversity as a resource, schools can facilitate well-being at the individual level (Schachner et al. 2016a), as well as positive intergroup attitudes in culturally diverse educational environments (Schwarzenthal et al. 2017).

\section{Notes}

1. In the literature, the term 'ethnic identity' or 'ethnic-racial identity' (especially in the U.S. context) is common. However, in the German context, discussion of cultural identities centre around heritage background and migration rather than ethnicity and race. In line with previous studies on cultural minority youth in Germany (e.g. Dimitrova et al. 2015, Vietze et al. 2018) we employ the term 'heritage identity' to refer to youth' feelings of belonging to the culture of their ethnic group and ancestors.

2. We explored an interaction effect between cultural identity dimensions. Adding a standardized interaction term between heritage and mainstream identity decreased model fit, $\mathrm{X} 2 / \mathrm{df}=3.55, p<.001 ; \mathrm{CFI}=.92 ; \mathrm{RMSEA}=.06$ (90\% Cl .05 to .08 ), was not significantly related to life satisfaction or school values, and did not change other paths in the model.

\section{Disclosure statement}

No potential conflict of interest was reported by the authors.

\section{Funding}

This work was supported by the Foundation of German Business (sdw) with a scholarship awarded to the first author at the University of Potsdam.

\section{Notes on contributors}

Jana Vietze is a PhD candidate and research assistant at the University of Potsdam, Germany. Jana holds a bachelor's degree in sociology and a magister degree in psychology from the University of Vienna. Her research interests include minority adolescents' acculturation and cultural identity formation, relational support by parents and peers, and diversity influences on academic achievement and well-being in schools. She is a doctoral 
scholarship holder of the Foundation of German Business (sdw) and German national representative of the Early Researchers' Union of the European Association of Developmental Psychology (EADP).

Linda P. Juang is a Professor in the Department of Inclusive Education at the University of Potsdam, Germany. Her research focuses on how experiences of immigration relate to adolescents' development and adjustment in school, family, and community contexts.

Maja K. Schachner is a postdoctoral researcher in Inclusive Education at the University of Potsdam, Germany, a fellow in the College for Interdisciplinary Educational Research, and president-elect of the Early Researchers' Union of the European Association of Developmental Psychology (EADP). Her main research interests include cultural diversity in schools, cross-ethnic friendships, acculturation and school-related outcomes of adolescents of immigrant background. She is the recipient of the 2015 George Butterworth Young Scientist Award of the EADP as well as the 2017 Early Career Award of the International Academy for Intercultural Research.

\section{ORCID}

Jana Vietze (D) http://orcid.org/0000-0002-8091-2127

Linda P. Juang (D) http://orcid.org/0000-0002-0308-6378

Maja K. Schachner (D) http://orcid.org/0000-0002-9388-7485

\section{References}

Andriessen, I., K. Phalet, and W. Lens. 2006. "Future Goal Setting, Task Motivation and Learning of Minority and Non-Minority Students in Dutch Schools." British Journal of Educational Psychology 76 (4): 827-850. doi:10.1348/000709906X148150.

Batista-Foguet, J., J. Fortiana, C. Currie, and J. Villalbi. 2004. "Socio-Economic Indexes in Surveys for Comparisons between Countries." Social Indicators Research 67 (3): 315-332. doi:10.1023/B:SOCl.0000032341.14612.b8.

Bender-Szymanski, D. 2012. "Assimilation, Segregation, or Integration? A Teaching Project Examining Approaches to Religious and Ideological Diversity in the Classroom." Intercultural Education 23 (4): 325-340. doi:10.1080/14675986.2012.724587.

Benet-Martínez, V., and J. Haritatos. 2005. "Bicultural Identity Integration (BII): Components and Psychosocial Antecedents." Journal of Personality 73 (4): 1015-1050. doi:10.1111/ j.1467-6494.2005.00337.x.

Berry, J. W., Y. H. Poortinga, S. M. Breugelmans, A. Chasiotis, and D. L. Sam. 2011. Cross-Cultural Psychology: Research and Applications. 16 th ed. Cambridge: Cambridge University Press.

Boyce, W., T. Torsheim, C. Currie, and A. Zambon. 2006. "The Family Affluence Scale as a Measure of National Wealth: Validation of an Adolescent Self-Report Measure." Social Indicators Research 78 (3): 473-487. doi:10.1007/s11205-005-1607-6.

Brown, B. B., and J. Larson. 2009. "Peer Relationships in Adolescence." In Handbook of Adolescent Psychology, edited by R. M. Lerner and L. Steinberg, 74-103. Hoboken: John Wiley \& Sons.

Civitillo, S., M. K. Schachner, L. P. Juang, F. J. R. van de Vijver, A. Handrick, and P. Noack. 2017. "Towards A Better Understanding of Cultural Diversity Approaches at School: A Multi-Informant and Mixed-Methods Study." Learning, Culture and Social Interaction 12: 1-14. doi:10.1016/j. Icsi.2016.09.002. 
Deci, E. L., and R. M. Ryan. 1987. "The Support of Autonomy and the Control of Behavior." Journal of Personality and Social Psychology 53 (6): 1024-1037.

Diener, E. D., R. A. Emmons, R. J. Larsen, and S. Griffin. 1985. "The Satisfaction with Life Scale." Journal of Personality Assessment 49 (1): 71-75. doi:10.1207/s15327752jpa4901_13.

Dimitrova, R., A. Aydinli, A. Chasiotis, M. Bender, and F. J. Van de Vijver. 2015. "Heritage Identity and Maintenance Enhance Well-being of Turkish-bulgarian and Turkish-german Adolescents." Social Psychology 46: 93-103. doi:10.1027/1864-9335/a000230.

Dimitrova, R., D. J. Johnson, and F. J. van de Vijver. 2017. "Ethnic Socialization, Ethnic Identity, Life Satisfaction and School Achievement of Roma Ethnic Minority Youth." Journal of Adolescence 62: 175-183. doi:10.1016/j.adolescence.2017.06.003.

Eccles, J. S., T. F. Adler, R. Futterman, S. B. Goff, C. M. Kaczala, and J. L. Meece. 1983. "Expectancies, Values, and Academic Behaviors." In Achievement and Achievement Motives, edited by J. T. Spence, 75-146. San Francisco, CA: Freeman.

Eccles, J. S. 2005. "Subjective Task Value and the Eccles Et Al. Model of Achievement-Related Choices." In Handbook of Competence and Motivation, edited by A. J. Elliot and C. S. Dweck, 105-121. New York: Guilford Publications.

Faas, D. 2008. "From Foreigner Pedagogy to Intercultural Education: An Analysis of the German Responses to Diversity and Its Impact on Schools and Students." European Educational Research Journal 7 (1): 108-123. doi:10.2304/eerj.2008.7.1.108.

Feliciano, C. 2012. "The Female Educational Advantage among Adolescent Children of Immigrants." Youth \& Society 44 (3): 431-449. doi:10.1177/0044118x11404441.

Feliciano, C., and Y. R. Lanuza. 2015. "The Immigrant Advantage in Adolescent Educational Expectations." International Migration Review 50 (3): 758-792. doi:10.1111/imre.12183.

Gartner, M., L. Kiang, and A. Supple. 2014. "Prospective Links between Ethnic Socialization, Ethnic and American Identity, and Well-Being among Asian-American Adolescents." Journal of Youth and Adolescence 43 (10): 1715-1727. doi:10.1007/ s10964-013-0044-0.

Göttsche, F. 2017. Bevölkerung Mit Migrationshintergrund Um 8,5 \% Gestiegen [Population with Migrant Background Grew by 8.5\%]. Wiesbaden: Statistisches Bundesamt.

Güngör, D., and M. H. Bornstein. 2013. "Gender and Developmental Pathways of Acculturation and Adaptation in Immigrant Adolescents." In Gender Roles in Immigrant Families. Advances in Immigrant Family Research, edited by S. S. Chuang and C. S. TamisLeMonda, 177-190. New York: Springer.

Hannover, B., C. C. Morf, J. Neuhaus, M. Rau, C. Wolfgramm, and L. Zander-Musić. 2013. “How Immigrant Adolescents' Self-Views in School and Family Context Relate to Academic Success in Germany." Journal of Applied Social Psychology 43 (1): 175-189. doi:10.1111/j.15591816.2012.00991.x.

Horenczyk, G. 2010. "Language and Identity in the School Adjustment of Immigrant Students in Israel." In Migration, Identität, Sprache und Bildungserfolg, edited by C. Allemann-Ghionda, P. Stanat, K. Göbel, and C. Röhner, 44-58. Beltz: Zeitschrift für Pädagogik, Beiheft.

Hu, L. T., and P. M. Bentler. 1999. "Cutoff Criteria for Fit Indexes in Covariance Structure Analysis: Conventional Criteria versus New Alternatives." Structural Equation Modeling: A Multidisciplinary Journal 6 (1): 1-55. doi:10.1080/10705519909540118.

Hughes, D., J. Rodriguez, E. P. Smith, D. J. Johnson, H. C. Stevenson, and P. Spicer. 2006. "Parents' Ethnic-Racial Socialization Practices: A Review of Research and Directions for Future Study." Developmental Psychology 42 (5): 747-770. doi:10.1037/0012-1649.42.5.747.

Hüpping, B., and P. Büker. 2014. "The Development of Intercultural Pedagogy and Its Influences on Primary Schools: Conclusions and Perspectives." Intercultural Education 25 (1): 1-13. doi:10.1080/14675986.2014.878072. 
Huynh, Q.-L., A.-M. D. Nguyen, and V. Benet-Martínez. 2011. "Bicultural Identity Integration." In Handbook of Identity Theory and Research, edited by S. J. Schwartz, K. Luyckx, and V. L. Vignoles, 827-842. New York, NY: Springer.

Juang, L. P., and M. Syed. 2010. "Family Cultural Socialization Practices and Ethnic Identity in College-Going Emerging Adults." Journal of Adolescence 33 (3): 347-354. doi:10.1016/j. adolescence.2009.11.008.

Juang, L. P., Y. Shen, S. Y. Kim, and Y. Wang. 2016. "Development of an Asian American Parental Racial-Ethnic Socialization Scale." Cultural Diversity and Ethnic Minority Psychology 22 (3): 417-431. doi:10.1037/cdp0000083.

Jugert, P., L. Leszczensky, and S. Pink. 2018. "The Effects of Ethnic Minority Adolescents' Ethnic Self-Identification on Friendship Selection." Journal of Research on Adolescence 28 (2): 379-395. doi:10.1111/jora.12337.

Kao, G., and M. Tienda. 1998. "Educational Aspirations of Minority Youth." American Journal of Education 106 (3): 349-384. doi:10.1086/444188.

Kiang, L., and A. J. Fuligni. 2009. "Ethnic Identity in Context: Variations in Ethnic Exploration and Belonging within Parent, Same-Ethnic Peer, and Different-Ethnic Peer Relationships." Journal of Youth and Adolescence 38 (5): 732-743. doi:10.1007/s10964-008-9278-7.

Kiang, L., A. J. Supple, and G. L. Stein. 2018. "Latent Profiles of Discrimination and Socialization Predicting Ethnic Identity and Well-Being among Asian American Adolescents." Journal of Research on Adolescence Advance online publication 1-16. doi: 10.1111/jora.12403.

Leszczensky, L., and A. G. Santiago. 2015. "The Developement and Test of a Measure of Youth's Ethnic and National Identity." Methods, Data, Analyses 9 (1): 24. doi:10.12758/ mda.2015.003.

Lynch, A. D., R. M. Lerner, and T. Leventhal. 2013. "Adolescent Academic Achievement and School Engagement: An Examination of the Role of School-Wide Peer Culture." Journal of Youth and Adolescence 42 (1): 6-19. doi:10.1007/s10964-012-9833-0.

Makarova, E., and D. Birman. 2016. "Minority Students' Psychological Adjustment in the School Context: An Integrative Review of Qualitative Research on Acculturation." Intercultural Education 27 (1): 1-21. doi:10.1080/14675986.2016.1144382.

Marcia, J. E. 1980. "Identity in Adolescence." In Handbook of Adolescent Psychology, edited by J. Adelson, 159-197. New York: Wiley.

Motti-Stefanidi, F., J. W. Berry, X. Chryssochoou, D. L. Sam, and J. Phinney. 2012. "Positive Immigrant Youth Adaptation in Context: Developmental, Acculturation, and Social Psychological Perspectives." In Realizing the Potential of Immigrant Youth, edited by A. S. Masten, K. Liebkind, and D. J. Hernandez, 117-158. New York, NY: Cambridge University Press.

Muthén, L. K., and B. O. Muthén. 1998[2011]. Mplus User's Guide. Los Angeles, CA: Muthén \& Muthén.

Nguyen, A.-M. D., and V. Benet-Martínez. 2013. "Biculturalism and Adjustment: A Meta-Analysis." Journal of Cross-Cultural Psychology 44 (1): 122-159. doi:10.1177/ 0022022111435097.

Pfafferott, I., and R. Brown. 2006. "Acculturation Preferences of Majority and Minority Adolescents in Germany in the Context of Society and Family." International Journal of Intercultural Relations 30 (6): 703-717. doi:10.1016/j.ijintrel.2006.03.005.

Phinney, J. S., G. Horenczyk, K. Liebkind, and P. Vedder. 2001. "Ethnic Identity, Immigration, and Well-Being: An Interactional Perspective." Journal of Social Issues 57 (3): 493-510. doi:10.1111/0022-4537.00225.

Ponizovsky, Y., R. Dimitrova, M. K. Schachner, and R. van de Schoot. 2013. "The Satisfaction with Life Scale: Measurement Invariance across Immigrant Groups." European Journal of Developmental Psychology 10 (4): 526-532. doi:10.1080/17405629.2012.707778. 
Rivas-Drake, D., E. K. Seaton, C. Markstrom, S. Quintana, M. Syed, R. M. Lee, S. J. Schwartz, A. J. Umaña-Taylor, S. French, and T. Yip. 2014. "Ethnic and Racial Identity in Adolescence: Implications for Psychosocial, Academic, and Health Outcomes." Child Development 85 (1): 40-57. doi:10.1111/cdev.12200.

Rogers, L. O., E. Y. Niwa, and N. Way. 2017. "The Friendships of Racial-Ethnic Minority Youth in Context." In Handbook on Positive Development of Minority Children and Youth, edited by N. J. Cabrera and B. Leyendecker, 267-280. New York, NY: Springer.

Ryan, A. M. 2000. "Peer Groups as a Context for the Socialization of Adolescents' Motivation, Engagement, and Achievement in School." Educational Psychologist 35 (2): 101-111. doi:10.1207/S15326985EP3502_4.

Schachner, M. K., F. J. R. van de Vijver, A. Brenick, and P. Noack. 2016b. "Who Is Friends with Whom? Patterns of Inter-And Intraethnic Friendships of Mainstream and Immigrant Early Adolescents in Germany." In Unity, Diversity and Culture, edited by P. Denoux, C. RolandLévy, and C. Sabatier, 238-244. Reims: International Association of Cross-Cultural Psychology.

Schachner, M. K., F. J. R. van de Vijver, and P. Noack. 2014. "Family-Related Antecedents of Early Adolescent Immigrants' Psychological and Sociocultural School Adjustment in Germany." Journal of Cross-Cultural Psychology 45 (10): 1606-1625. doi:10.1177/0022022114543831.

Schachner, M. K., F. J. R. van de Vijver, and P. Noack. 2018. "Acculturation and School Adjustment of Early-Adolescent Immigrant Boys and Girls in Germany - Conditions in School, Family, and Ethnic Group." The Journal of Early Adolescence 38 (3): 352-384. doi:10.1177/0272431616670991.

Schachner, M. K., P. Noack, F. J. R. van de Vijver, and K. Eckstein. 2016a. "Cultural Diversity Climate and Psychological Adjustment at School - Equality and Inclusion versus Cultural Pluralism." Child Development 87 (4): 1175-1191. doi:10.1111/cdev.12536.

Schotte, K., P. Stanat, and A. Edele. 2017. "Is Integration Always Most Adaptive? the Role of Cultural Identity in Academic Achievement and in Psychological Adaptation of Immigrant Students in Germany." Journal of Youth and Adolescence 47 (1): 16-37. doi:10.1007/ s10964-017-0737-x.

Schwarzenthal, M., M. K. Schachner, F. J. R. van de Vijver, and L. P. Juang. 2017. “Equal but Different: Effects of Equality/Inclusion and Cultural Pluralism on Intergroup Outcomes in Multiethnic Classrooms." Cultural Diversity and Ethnic Minority Psychology 24 (2): 260-271. doi:10.1037/cdp0000173.

Söhn, J., and V. Özcan. 2006. "The Educational Attainment of Turkish Migrants in Germany." Turkish Studies 7 (1): 101-124. doi:10.1080/14683840500520626.

Stark, T. H., L. Leszczensky, and S. Pink. 2017. "Are There Differences in Ethnic Majority and Minority Adolescents' Friendships Preferences and Social Influence with Regard to Their Academic Achievement?" Zeitschrift für Erziehungswissenschaft 20 (3): 475-498. doi:10.1007/s11618-017-0766-y.

Steinmayr, R., and B. Spinath. 2010. "Konstruktion Und Erste Validierung Einer Skala Zur Erfassung Subjektiver Schulischer Werte (SESSW) [Construction and First Validation of the Scale Assessing Subjective Task Values in a School Context]." Diagnostica 56 (4): 195-211. doi:10.1026/0012-1924/a000023.

Stevick, E. D. 2017. "'Can I Borrow Your Glasses?' A Prescription for Learning to See the Cultural Roots of Identity Terms and Implicit Categories through Others' Lenses." Intercultural Education 28 (6): 543-556. doi:10.1080/14675986.2017.1405529.

Suárez-Orozco, C., and D. B. Qin. 2006. "Gendered Perspectives in Psychology: Immigrant Origin Youth." International Migration Review 40 (1): 165-198. doi:10.1111/j.17477379.2006.00007.x. 
Syed, M., and M. J. D. Juan. 2012. "Birds of an Ethnic Feather? Ethnic Identity Homophily among College-Age Friends." Journal of Adolescence 35 (6): 1505-1514. doi:10.1016/j. adolescence.2011.10.012.

Thijs, J., and M. Verkuyten. 2014. "School Ethnic Diversity and Students' Interethnic Relations." British Journal of Educational Psychology 84 (1): 1-21. doi:10.1111/bjep.12032.

Titzmann, P. F., and L. P. Juang. 2017. "Immigrant Adolescents: Opportunities and Challenges." In Emerging Trends in the Social and Behavioral Sciences: An Interdisciplinary, Searchable, and Linkable Resource, edited by R. Scott, M. C. Buchmann and S. M. Kosslyn, 1-14. New Jersey, NJ: J. Wiley \& Sons.

Umaña-Taylor, A. J., R. Bhanot, and N. Shin. 2006. "Ethnic Identity Formation during Adolescence the Critical Role of Families." Journal of Family Issues 27 (3): 390-414. doi:10.1177/0192513X05282960.

Umaña-Taylor, A. J., S. Douglass, K. A. Updegraff, and F. F. Marsiglia. 2017. "A Small-Scale Randomized Efficacy Trial of the Identity Project: Promoting Adolescents' Ethnic-Racial Identity Exploration and Resolution." Child Development. doi:10.1111/cdev.12755.

UNESCO. 2006. "Guidelines for Intercultural Education." In UNESCO: Guidelines for Intercultural Education, edited by Division for the Promotion of Quality Education Section of Education for Peace and Human Rights, Education Sector Paris, 31-39. Paris, France: UNES.

van de Vijver, F. J. 2017. "Challenges in the Study of Adolescent and Acculturative Changes." Journal of Adolescence 62: 226-229. doi:10.1016/j.adolescence.2017.08.004.

Vedder, P., and M. van Geel. 2017. "Cultural Identity Development as a Developmental Resource." In Handbook on Positive Development of Minority Children and Youth, edited by N. J. Cabrera and B. Leyendecker, 123-137. New York, NY: Springer.

Vietze, J., L. P. Juang, M. K. Schachner, and H. Werneck. 2018. "Feeling Half-Half? Exploring Relational Variation of Turkish-Heritage Young Adults' Cultural Identity Compatibility and Conflict in Austria." Identity 18 (1): 60-76. doi:10.1080/15283488.2017.1410159.

Wang, Y., and A. D. Benner. 2016. "Cultural Socialization across Contexts: Family-Peer Congruence and Adolescent Well-Being." Journal of Youth and Adolescence 45 (3): 594-611. doi:10.1007/s10964-016-0426-1.

Wang, Y., A. D. Benner, and S. Y. Kim. 2015. "The Cultural Socialization Scale: Assessing Family and Peer Socialization toward Heritage and Mainstream Cultures." Psychological Assessment 27 (4): 1452-1462. doi:10.1037/pas0000136.

Ward, C. 2001. "The A, B, Cs of Acculturation." In The Handbook of Culture and Psychology, edited by D. Matsumoto, 411-445. New York: Oxford University Press. 